\title{
DIAMINO FLUORETO DE PRATA: UMA REVISÃO DE LITERATURA
}

\section{DIAMINE SILVER FLUORIDE: A LITERATURE REVIEW}

\author{
Rafael Gomes Ditterich ${ }^{1}$, Marissol C. M. O. Vasconcellos Romanelli ${ }^{2}$, \\ Márcia Cristina Rastelli ${ }^{3}$, Gislaine Denise Czlusniak ${ }^{4}$, \\ Denise Stadler Wambier ${ }^{5}$ \\ 1 Universidade Federal do Paraná - UFPR, Curitiba, PR, Brasil \\ 2 Cirurgiã dentista, Curitiba, PR \\ 3 Cirurgiã dentista, Ponta Grossa, PR \\ 4 Universidade Estadual de Ponta Grossa - UEPG, Programa de Mestrado em Odontologia, \\ Campus em Uvaranas, Ponta Grossa, PR \\ 5 Autor para contato: Universidade Estadual de Ponta Grossa - UEPG, Departamento de \\ Odontologia e Programa de Mestrado em Odontologia, Campus em Uvaranas, \\ Ponta Grossa, PR, Brasil; (42) 3220-3111; e-mail: dswambier@uepg.br
}

Recebido para publicação em 18/05/2006

Aceito para publicação em 30/05/2006

\section{RESUMO}

A prevenção e o tratamento da doença cárie continuam sendo um dos maiores desafios da Odontologia. Sabe-se que devido a fatores como transmissibilidade de bactérias cariogênicas da mãe para o filho, dieta inadequada e higiene deficiente, a cárie atinge cada vez mais pacientes infantis. A presente revisão de literatura propõe como alternativa para o tratamento da cárie de estabelecimento precoce, o diamino fluoreto de prata, avaliando a sua eficiência como agente cariostático, relatando suas vantagens, indicações, método de aplicação e limitações.

Palavras-chave: agentes cariostáticos, cárie dentária, bebês

\begin{abstract}
The prevention and treatment of the caries disease are still the major challenges in Dentistry. It is known that because of factors such as the transmissibility of bacteria from mother to child, an inadequate diet and deficient hygiene, dental caries in children increases all the time. The present literature review proposes the use of diamine silver fluoride as an alternative for the treatment of early childhood caries, evaluating its efficiency as a cariostatic agent and describing its advantages and indications, as well as its applications and limitations.
\end{abstract}

Key words: cariostatic agents, dental caries, babies 


\section{Introdução}

As manifestações da doença cárie, principalmente em crianças com menos de três anos de idade é uma condição crítica. A resolução do quadro clínico instalado, conhecido como cárie de acometimento precoce, não é tarefa simples para a Odontopediatria. Em geral, as lesões apresentam aspecto agudo de rápida evolução, podem afetar vários dentes, determinando até a perda do elemento dental. Esta doença iniciada nos primeiros anos de vida ocasiona danos futuros, pois os dentes decíduos têm papel importante na erupção e desenvolvimento normal dos dentes permanentes, crescimento e desenvolvimento da face (Rodrigues et al., 1989).

Os fatores de risco, como higienização bucal deficiente, hábitos inadequados (amamentação noturna, chupeta com mel ou açúcar, elevado consumo de alimentos açucarados), colonização precoce pelo Streptococcus mutans e ainda, a carência de orientação aos pais, propiciam uma rápida evolução das lesões cariosas (Alaluusua e Renkonen, 1983; Köhler et al., 1984; Reisine; Litt e Tinanoff, 1994; Tinanoff e O’Sullivan, 1997; Quiñonez et al., 2001; Hallett e O’Rourke, 2003; Ditterich et al., 2004).

A Odontologia conta com vários métodos para prevenção e controle da cárie dentária e esses devem ser disponibilizados ainda nos primeiros anos de vida. Ações educativas direcionadas às gestantes, e atendimento precoce de bebês possibilita o emprego de procedimentos não invasivos, mais eficazes e menos traumáticos. Infelizmente, a falta de acesso aos cuidados odontológicos em momento oportuno, permite a instalação da doença que requer cuidados especiais. Assim, quando o paciente infantil é acometido por cárie aguda, torna-se necessário o uso de agentes de controle desse processo até que a criança possa receber tratamento restaurador convencional, sem que piore ainda mais o seu estado de saúde bucal. Concomitantemente, haverá tempo para que os seus responsáveis consigam adaptá-las aos novos hábitos alimentares e à realização do controle mecânico do biofilme dental.

Um dos agentes de controle que tem se mostrado eficaz é o diamino fluoreto de prata, produto com propriedades preventivas e cariostáticas (Yamaga et al., 1972). Ele já foi bastante utilizado na prevenção de cárie em sulcos e fissuras (Massler, 1977 apud
Maciel, 1988), apresenta facilidade de aplicação, baixo custo e pode ser utilizado em larga escala (Bijella et al., 1991). Mesmo com o resultado anti-estético de sua aplicação, ele deve ser empregado como uma opção de tratamento em crianças de pouca idade, principalmente em nível de Saúde Pública, onde as condições de trabalho são muitas vezes limitadas (Wambier; Bosco, 1995).

O objetivo deste trabalho é realizar uma revisão de literatura, considerando as propriedades físico-químicas e mecanismo de ação do diamino fluoreto de prata a fim de contribuir com informações que auxiliem o clínico na correta indicação desse produto.

\section{Histórico e evolução}

As pesquisas sobre o diamino fluoreto de prata são tão antigas quanto os estudos sobre cárie dentária. Estas iniciaram-se no Japão, com intuito de criar uma substância que combatesse efetivamente a alta incidência de cárie dentária em crianças desse país. Na época já existiam especulações sobre um provável efeito protetor nos dentes originado da aplicação de uma solução chamada “ohaguro”. Essa solução, de cor preta, era utilizada com finalidade cosmética e servia para distinguir as mulheres comprometidas. Este hábito foi adotado há milhares de anos pelos ancestrais japoneses e há mais de cem anos este costume foi proibido. Um fato interessante observado com o uso desse corante foi a redução de cáries e também a ausência de mobilidade dentária. A partir dessa observação inicial, houve interesse pelos efeitos positivos do "ohaguro" (Maciel, 1988), o que motivou o desenvolvimento de investigações científicas, procurando elucidar sua composição, mecanismo de ação e o papel preventivo contra cáries.

Pesquisas esclareceram que o "ohaguro" era composto por uma base de ferro obtida pela mistura de limalha de ferro aquecida, chá, ácidos de alimentos açucarados, água, amido, levedura, um vinho de arroz conhecido como saque e nozes amargas de uma árvore chinesa chamada "fushiko" (Ai et al.1965 apud Maciel, 1988). O tanato férrico que se precipita na superfície dentária era o produto resultante da reação entre a solução de ferro e o ácido tânico (“fushiko”). O interesse 
dos pesquisadores pelo "ohaguro" devia-se ao fato de que o ferro era o seu principal componente e pela reação química deste com as substâncias inorgânicas do dente, ocasionando paralisação e prevenção da cárie. A partir deste entendimento inicial, estudiosos japoneses iniciaram pesquisas com outros íons metálicos, como a prata, para verificar se poderia ser encontrada propriedade cariostática semelhante a do "ohaguro".

Com o objetivo de se conseguir uma maior resistência do dente, vários experimentos foram realizados utilizando-se de substâncias químicas. Dentre estas, destacaram-se o nitrato de prata $\left(\mathrm{AgNO}_{3}\right)$ e o fluoreto de sódio (NaF). Estas soluções, quando aplicadas topicamente sobre as superfícies dentárias, formavam respectivamente: fosfato de prata $\left(\mathrm{AgPO}_{4}\right)$ e fluoreto de cálcio $\left(\mathrm{CaF}_{2}\right)$, conferindo uma maior resistência à cárie dentária. Com estes resultados benéficos, ocorriam também reações indesejáveis, ou seja, perda de íons cálcio $\left(\mathrm{Ca}^{++}\right)$e de íons fosfato $\left(\mathrm{PO}_{4}^{-3}\right)$, fenômenos estes que poderiam ser considerados como uma forma artificial de descalcificação (Maciel, 1988).

Baseados nas pesquisas desenvolvidas até então, e buscando melhorar as propriedades cariostáticas dos primeiros produtos investigados, Yamaga e Yokomizo (1969 apud Bijella et al., 1991) introduziram um novo agente cariostático que recebeu o nome de diamino fluoreto de prata ou fluoreto de amônia de prata. Tratase de um líquido incolor com $\mathrm{pH}$ próximo de oito e que somou as vantagens do nitrato de prata com o fluoreto de sódio, sem perda mineral (Ando, 1981; Wambier e Bosco, 1995; Medeiros et al., 1998). As pesquisas tiveram continuidade e com o intuito de explorar ao máximo os potenciais benéficos da prata e do flúor quando aplicados topicamente, uma solução de diamino fluoreto de prata a $30 \%$ foi testada, verificando-se que ocorria uma perda mínima de íons $\mathrm{Ca}^{++} \mathrm{ePO}_{4}^{-3}$ (Nishino, 1969 apud Maciel, 1988).

\section{Mecanismo de ação}

Para que se possa entender o mecanismo de ação do diamino fluoreto de prata como agente químico preventivo da doença cárie, é necessário o conhecimento do mecanismo de ação do flúor e do nitrato de prata. O objetivo dos pesquisadores japoneses na concepção deste agente cariostático foi o de minimizar as desvantagens ocorridas quando se utiliza o flúor e o nitrato de prata (perda mineral). Estas desvantagens são melhor compreendidas ao se observar a reação química entre os agentes preventivos e a superfície dental (Maciel, 1988; Grossi, 1998; Rocha et al., 1999). Nas aplicações tópicas ou bochechos com altas concentrações de flúor (mais que 300 ppm) observase a seguinte reação química:

$$
\mathrm{Ca}_{10}\left(\mathrm{PO}_{4}\right)_{6}(\mathrm{OH})_{2}+20 \mathrm{NaF} \rightarrow 10 \mathrm{CaF}_{2}+6 \mathrm{Na}_{3} \mathrm{PO}_{4}+\mathrm{NaOH}
$$

A hidroxiapatita é decomposta formando $\mathrm{CaF}_{2}$ que se deposita na superfície do dente e em fosfato de sódio que é subseqüentemente liberado, ocorrendo também uma pequena parte da reação que forma fluorapatita. Os autores acreditam que o fluoreto de cálcio formado na superfície do dente é instável e passível de ser removido pela escovação (Yamaga et al., 1972; Maciel, 1988; Rodrigues et al., 1989; Grossi, 1998).

A aplicação de uma solução amoniacal de nitrato de prata foi muito utilizada para o controle da cárie dentária. Em sua reação química esta solução se dissocia em um íon de diamino de prata, $\mathrm{Ag}\left(\mathrm{NH}_{3}\right)$, que não é auto-limitante, penetrando tanto em dentina tubular sã como na cariada. O nitrato de prata mancha estas dentinas diferentemente. Este manchamento ocorre em quatro camadas distintas. A primeira, com íons leve de prata que forma uma camada preta, uma segunda formada por uma dentina marrom escura envolvendo a dentina necrótica e a cariada. Isto ocorre por meio da reação entre o processo carioso e as proteínas da matriz da dentina que sofrem uma desnaturação, assim, estas proteínas irão se combinar com a prata formando proteinato de prata, que é marrom escuro ou poderão reduzir os íons de prata que é a prata coloidal, também marrom. A terceira camada não é pigmentada, e pode representar a área afetada pelo ácido com o material intra-tubular degenerado, formando uma dentina 
desmineralizada. Aúltima camada é formada por uma zona preta com precipitado de partículas de prata livre, localizados dentro dos túbulos vitais da dentina (Ando, 1981; Maciel, 1988; Grossi, 1998).

A prata é um íon do grupo dos metais pesados que geralmente une-se às proteínas levando a coagulação, sendo capaz de formar nesta reaçãoproteína de prata que exerce efeito inibitório sobre uma variedade de enzimas. O íon prata tem potente efeito bac- tericida. Esta propriedade antimicrobiana se explica por meio de sua ação oligodinâmica, ou seja, mesmo em baixas concentrações é mantido um equilíbrio protoplasmático. Ele também possui uma ação antisséptica e adstringente, que pode ser utilizada em tratamentos de estomatites, gengivites e periodontites (Yamaga et al., 1972; Maciel, 1988; Andrade et al., 1992; Grossi, 1998). A reação que descreve o nitrato de prata com a superfície do dente é a seguinte:

$$
\mathrm{Ca}_{10}\left(\mathrm{PO}_{4}\right)_{6}(\mathrm{OH})_{2}+20 \mathrm{AgNO}_{3} \rightarrow 6 \mathrm{Ag}_{3} \mathrm{PO}_{4}+10 \mathrm{Ca}\left(\mathrm{NO}_{3}\right)_{2}+\mathrm{Ag}_{2} \mathrm{O}+\mathrm{H}_{2} \mathrm{O}
$$

$\mathrm{O}$ fosfato de prata $\left(\mathrm{Ag}_{3} \mathrm{PO}_{4}\right)$ é pouco solúvel e inicialmente amarelo, mas quando exposto à luz ou a agentes redutores, torna-se enegrecido precipitandose sobre a superfície dental. Quanto ao nitrato de cálcio [Ca $\left(\mathrm{NO}_{3}\right)_{2}$ ], ele é muito solúvel em água e o cálcio é facilmente perdido (Maciel, 1988; Grossi, 1998).

Para aproveitar os benefícios do flúor e da prata como substâncias que oferecem resistência aos tecidos dentários, surgiu o diamino fluoreto de prata em uma formulação que evita os efeitos negativos da perda de íons fosfato e cálcio. Os produtos resultantes da aplicação do diamino fluoreto de prata são: fluoreto de cálcio, fosfato de prata e proteinato de prata, os quais são menos solúveis (Rodrigues et al., 1989; Grossi, 1998), como exemplificado pela reação abaixo:

$$
\mathrm{Ca}_{10}\left(\mathrm{PO}_{4}\right)_{6}(\mathrm{OH})_{2}+\mathrm{Ag}\left(\mathrm{NH}_{3}\right)_{2} \mathrm{~F} \rightarrow 6 \mathrm{Ag}_{3} \mathrm{PO}_{4}+10 \mathrm{Ca}\left(\mathrm{NO}_{3}\right)_{2}+\mathrm{Ag}_{2} \mathrm{O}+\mathrm{H}_{2} \mathrm{O}
$$

O diamino fluoreto de prata age tanto na porção inorgânica do elemento dentário quanto na porção orgânica (Maciel, 1988; Rodrigues et al., 1989; Andrade et al., 1992), sendo o fluoreto de sódio responsável pela parte inorgânica que é a hidroxiapatita e o nitrato de prata pela porção orgânica que são as proteínas (Maciel, 1988; Rodrigues et al., 1989; Andrade et al., 1992; Rocha et al., 1999).

Yamaga et al. (1972); Shimizu e Kawagoe (1976) descreveram três mecanismos de ação quando o diamino fluoreto de prata foi empregado na prevenção de cáries recorrentes. O primeiro mecanismo está relacionado à obstrução dos túbulos dentinários, observado por meio de microradiografias. Foram encontradas alterações morfológicas, com túbulos mais estreitos ou obturados e notou-se também a presença de prata e de seus compostos no interior dos túbulos. Essa obliteração dificulta a difusão de ácidos e a invasão bacteriana. O segundo mecanismo é por meio de sua ação cariostática como produto da reação entre o diamino fluoreto de prata e o componente mineral do dente. Sabe-se que tratamentos com flúor aumentam a resistência da dentina peri e intertubular à desmineralização ácida, retardando a penetração deste nas camadas mais profundas. O íon flúor do diamino fluoreto de prata penetra de 50 a $100 \mu \mathrm{m}$ em profundidade, sendo a fluorapatita tão estável que resiste à descalcificação por agentes ácidos ou quelantes. O terceiro mecanismo é caracterizado pela ação anti-enzimática dos produtos da reação entre o diamino fluoreto de prata e o componente orgânico, que é a proteína dentinária que tem sua resistência aumentada à colagenase e à tripsina.

\section{Composição e formas comerciais}

O diamino fluoreto de prata, conhecido também como solução cariostática, apresenta em sua composição hidróxido de amônia, nitrato de prata, hidróxido de cálcio, ácido fluorídrico e solvente. No Brasil são comercializados nas concentrações de 10\%, 12\%, 30\% e 38\%, com as marcas comerciais:

- Cariostatic ${ }^{\circledR}$ (Inodon): contém em cada $\mathrm{mm}^{3}$; $100 \mathrm{mg}$ de diamino fluoreto de prata.

- Bioride ${ }^{\circledR}$ (Herpe), Cariestop ${ }^{\circledR}$ (Biodinâmica): 
possui $120 \mathrm{mg}$ em cada $\mathrm{mm}^{3}$.

- Safluoride de Walter ${ }^{\circledR}$ (Polidental), Cariestop ${ }^{\circledR}$

(Biodinâmica): possui 300 mg em cada $\mathrm{mm}^{3}$.

- Saforide $\AA$ : contém 380 mg em cada mm³ .

\section{Propriedades físico-químicas}

Várias propriedades foram atribuídas ao diamino fluoreto de prata, entre elas: tornar o esmalte dental mais resistente, inibir a formação de placa, diminuir a produção ácida dos microorganismos na dentina cariada, reduzir a população de Streptococcus mutans e obliterar os canalículos dentinários expostos, estabelecendo uma ação cariostática e impedindo o desenvolvimento de cárie (Wambier e Bosco, 1995; Guedes-Pinto e Issáo, 1999).

A solução de diamino fluoreto de prata a 38\% (Saforide ${ }^{\circledR}$ ) aumenta a resistência dos dentes contra a cárie e apresenta efeito antibacteriano sobre Streptococcus mutans (Igarashi, 1978), pois inibe a aderência e crescimento dessas bactérias nas superfícies dentárias (Tsutsumi, 1981 apud Maciel, 1988).

A ação antimicrobiana foi avaliada em estudo “in vitro" (Montandon; Sperança, 2000) comparandose três concentrações do diamino fluoreto de prata ( $10 \%, 12 \%$ e $30 \%)$ e nitrato de prata a $2 \%$. O resultado mostrou que quanto maior a concentração da solução cariostática, maior é o seu efeito antibacteriano.

\section{Indicações}

Várias indicações clínicas foram atribuídas ao diamino fluoreto de prata, tais como: redução da sensibilidade da dentina, tratamento de canal radicular, detecção de cáries incipientes, endurecimento da dentina amolecida para facilitar o preparo cavitário e protético, prevenção de cáries recorrentes e promoção do aumento da força de união do cimento fosfato de zinco à superfície dentária (Yamaga et al., 1972; Rodrigues et al., 1989; Andrade et al., 1992). Mas entre todas as indicações mencionadas, a realmente importante é a aplicação do diamino fluoreto de prata com o objetivo de paralizar as lesões de cárie agudas em crianças, principalmente nos primeiros anos de vida. Na fase de adequação do meio bucal esse produto permite interromper o processo carioso, reduzindo a atividade bacteriana enquanto se promove a mudança dos hábitos inadequados (dietéticos e de higiene) que contribuíram para a instalação da doença.

\section{Modo de aplicação}

Segundo Guedes-Pinto e Issáo (1999), antes da aplicação do diamino fluoreto de prata, deve-se informar os responsáveis que na região em que o processo da cárie estiver presente, ocorrerá o escurecimento. Eles preconizam a técnica de aplicação abaixo citada:

1. Profilaxia com pedra-pomes e água;

2. Remoção da dentina amolecida com curetas;

3. Lavagem e secagem;

4. Proteção dos tecidos moles com vaselina ou manteiga de cacau;

5. Isolamento relativo e secagem do campo operatório;

6. Aplicação com bolinha de algodão ou cotonete umedecido, por 3 minutos.

Caso ocorra contato desta substância com tecido mole, por exemplo, a gengiva, formando uma área esbranquiçada, deve-se neutralizar a ação do diamino com solução salina a 3\%. Se acontecer contato do produto com a pele e roupas, recomenda-se lavar com água, amônia ou água oxigenada.

Para melhor eficácia no tratamento as reaplicações devem ser feitas trimestralmente, maximizando assim a ação cariostática da solução. Além disso, o controle do processo carioso deve ser realizado de seis em seis meses (Massao et al., 1998; Rocha et al., 1999).

\section{Discussão}

O tratamento restaurador convencional não é o modo mais eficiente para o controle da cárie na dentição decídua. Primeiro pelas dificuldades de tratamento do ponto de vista clínico em tenra idade, segundo porque a cárie na dentição decídua apresenta rápida 
progressão (Nishino e Yoshida,1969). Em termos de atendimento clínico, especialmente na Odontopediatria, torna-se necessário a utilização de um agente efetivo que possa controlar e paralisar a doença cárie com uma técnica de aplicação simples. Argumentando que as soluções de fluoretos ou de nitrato de prata, utilizadas para a prevenção da instalação de cáries, removem respectivamente fosfato e cálcio das estruturas dentais, Yamaga et al. (1972), propuseram o diamino fluoreto de prata a 38\% como agente cariostático. Com certeza esse produto passou a ser um auxiliar na clínica infantil, permitindo o uso de medidas práticas e efetivas de controle da cárie.

Suzuki (1973) estudou o efeito da aplicação tópica de cariostático, e após 18 meses, observou que a incidência da cárie dentária foi reduzida em 42,1\% nos molares decíduos e em $24,43 \%$ nos primeiros molares permanentes. No Brasil, Bijella et al. (1991), estudaram o efeito da aplicação de cariostático a 12\%, e constataram redução da incidência de cárie nos primeiros molares permanentes da ordem de $63 \%$ nas aplicações trimestrais e de 43,93\% nas aplicações semestrais.

Outro fato de importância é que as regiões de fóssulas e fissuras são mais suscetíveis às cáries que as superfícies lisas, isto por razões morfológicas. Paradoxalmente, é difícil a detecção de lesões incipientes nestas regiões. A situação se agrava pelo fato de os tratamentos preventivos com fluoretos tópicos atuarem de forma menos efetiva nas mesmas e pela dificuldade que oferecem a uma limpeza adequada por meio de escovação (Maciel, 1988; Grossi, 1998).

Preocupados com a alta incidência de cáries em fóssulas e fissuras no primeiro molar permanente de crianças japonesas, Sato e Saito (1970 apud Maciel, 1988), fizeram uma avaliação clínica do efeito preventivo do diamino fluoreto de prata sobre as mesmas. Foram selecionadas 25 crianças que apresentavam os primeiros molares inferiores hígidos, onde o molar direito recebeu três aplicações de diamino fluoreto de prata por três minutos, com intervalo de dois dias e o molar esquerdo foi deixado sem tratamento, como controle. Os resultados obtidos pelos autores expressaram que houve nítida prevenção de cárie no grupo que recebeu cariostático (76\%) em relação ao grupo controle (12\%).
A aplicação clínica do diamino fluoreto de prata apresenta algumas desvantagens, segundo GuedesPinto e Issáo (1999) como: escurecimento, em função de terem um poder de pigmentação alto pela precipitação da prata e em concentrações altas, podem causar irritação pulpar.

No tratamento com o diamino fluoreto de prata a $38 \%$ em cavidades profundas houve comprometimento pulpar com o aparecimento de abscesso (Russo et al., 1986), enquanto que na concentração de $10 \%$ não se percebeu tais alterações (Russo et al., 1987; Andrade et al., 1992).

Um dos pontos relevantes a ser discutido é o aspecto antiestético provocado pela pigmentação após o uso do cariostático, mas acredita-se que a validade do benefício é bem maior que o prejuízo estético (Wambier e Bosco, 1995; Massao et al., 1996). Massao et al. (1997 apud Rocha et al., 1999) em entrevista com os pais de crianças que receberam aplicação de cariostáticos, observaram que, apesar de não gostarem do aspecto enegrecido das lesões cariosas, a rejeição diminuía com o decorrer do tempo de forma significante, provavelmente devido à nova visão do manejo da doença cárie.

A redução de bactérias cariogênicas obtida pelo selamento cavitário e aplicação de agentes cariostáticos é uma etapa importante que antecede o tratamento odontológico reabilitador. Assim, a associação entre cariostático e tratamento restaurador atraumático é um opção terapêutica de grande valor, principalmente nas crianças portadores de cárie de acometimento precoce (Chibinski, Tanaka,Wambier 2005).

A aplicação do diamino fluoreto de prata produz um impacto inicial ("tratamento de choque"), promovendo expressiva redução bacteriana nos níveis salivares de $\mathrm{S}$. mutans na saliva, mesmo com uma única aplicação (Wambier et al., 2002). Um fato que não deve ser esquecido é que a recolonização bacterina ocorre poucos dias após a aplicação do cariostático (Wambier et al., 2002). Isto implica na necessidade do controle efetivo e rotineiro do biofilme, habitado por bactérias potencialmente cariogenicas, e verdadeiro responsável pelo desequilíbrio no meio bucal. Esse objetivo é alcançado mediante empenho dos profissionais em consultas educativas, objetivando a mudança de hábitos inadequados. 


\section{Conclusões}

O tratamento odontológico infantil dos portadores de cárie de acometimento precoce, principalmente nos primeiros anos de vida pode representar um quadro extremamente difícil. Requer profissionais habilitados no atendimento, pois em geral esses pacientes são imaturos e pouco receptivos ao tratamento. Nesses casos, o profissional deve levar em consideração os materiais odontológicos que apresentem uma alta eficiência com simplicidade de aplicação. $\mathrm{O}$ diamino fluoreto de prata preenche esses requisitos, além de apresentar um baixo custo, razão pela qual é indicado como opção no controle da cárie em saúde pública. As desvantagens podem ser contornadas informando-se aos pais sobre o aspecto enegrecido dos dentes, como uma situação provisória, pois no futuro a adoção de um tratamento reabilitador pode restabelecer a estética. Deve-se ressaltar que o aspecto antiestético não tem grande significado, considerando que a criança tem sua sensibilidade diminuída e a doença controlada.

\section{REFERÊNCIAS}

1. ANDO, T. Indicações do uso do Diaminofluoreto de prata (Saforide) em odontopediatria. RGO, v. 29, n. 1, p. 48-49, 1981.

2. ANDRADE, K. C. G. E.; MACIEL, S. M.; GUEDES PINTO, A. C.; JAEGER, R. G. Reações da dentina cariada após aplicação do Diamino fluoreto de prata a $10 \%$ : estudo através de microscópio eletrônico de varredura. RBO, v. 49, n. 6, p. 31-36, nov./dez. 1992.

3. ALALUUSUA, S.; RENKONEN, O. V. Streptococcus mutans establishment and dental caries experience in children from 2 to 4 years old. Scan J Dent, v. 91, p. 453-7, 1983.

4. BIJELLA, M. F. T. B.; BIJELLA, V. T.; SILVA, M. S. M. B.; LOPES, E. S. Avaliação clínica da aplicação de Diamino-fluoreto de prata a $12 \%$ (Bioride) na dentição decídua e seu efeito na incidência de cárie em primeiros molares permanentes. Revista Paulista de Odontologia, v. 13, n. 5, p. 28-35, set./out. 1991.

5. DITTERICH, R. G;; ROMANELLI, M. C.; RASTELLI, M. C.; WAMBIER, D. S. Cárie de acometimento precoce: uma revisão. Publ UEPG Ci Biol Saúde, v. 10, n. 3/4, p. 33-41, set./dez. 2004.

6. CHIBINSKI, A.C.R.; TANAKA, F.; WAMBIER, D.S. Diamino fluoreto de prata: Recurso substimado em Saúde Pública? Rev Ibero-am Odontopediatr odontol Bebê, v.8, n.43, p.253-63,2005
7. GROSSI, E. H. U. Diamino fluoreto de prata: atuação sobre o esmalte dental. Londrina. 1998. 20 p. Monografia (Especialização em Odontopediatria) - Associação Odontológica do Norte do Paraná.

8. GUEDES-PINTO, A. C.; ISSÁO, M. Manual de Odontopediatria. 10. ed. São Paulo: Pancast, 1999. p.184-185.

9. HALLET, K.B.; O’ROURKE, P.K. Social and behavioural determinants of early childhood caries. Aust Dent J, v.48, n.1, p.27-33, 2003.

10. IGARASHI, S. Bacteriological study on diammine silver fluoride. Changes of the proportional distribuition of Streptococcus mutans in dental plaque by topical application Of Ag $\left(\mathrm{NH}_{3}\right)_{2} \mathrm{~F}$ And Its Anti-Bacterial Effect. Jap J Pedod., v. 16, n. 1, p. 1-18, 1978.

11. KÖHLER, B.; ANDRÉEN, I.; JOHNSSON, B. The effect of caries-preventive measures in mothers on dental caries and oral presence of the bacteria Streptococcus mutans and lactobacilli in their children. Arch Oral Biol, v. 29, p. 879-83, 1984.

12. MACIEL, S. M. Estudo clínico da ação do diamino fluoreto de prata a $10 \%$ sobre superfícies oclusais de molares decíduos. São Paulo. 1988. 173 p. Dissertação (Mestrado Em Odontopediatria) - Faculdade de Odontologia, Universidade de São Paulo.

13. MASSAO, J. M.; SUED, M. L.; GIORDANO, D. V.; GANO, R. S.; SANTOS, F. A.; CARNEIRO, A. A. Filosofia da clínica de bebês da Unigranrio-RJ. RBO, v. 53, n. 5, p. 6-13, set./out. 1996.

14. MEDEIROS, U. V.; MIASATO, J. M.; MONTE ALTO, L. A.; RAMOS, M. E. B.; SOVIERO, V. L. Efeito cariostático e preventivo do diamino fluoreto de prata a 30 por cento em bebês. RBO, v. 55, n. 6, p. 340-4, nov./dez. 1998.

15. MONTANDON, E. M.; SPERANÇA, P. A. Estudo comparativo in vitro da atividade antimicrobiana de agentes cariostáticos à base de Diamino fluoreto de prata. Jornal Brasileiro de Odontopediatria e Odontologia do bebê, v. 3, n. 16, p. 465-474, nov./dez. 2000.

16. NISHINO, M.; YOSHIDA, S. Clinical effects of diammine silver fluoride on dental caries on pulp of deciduos teeth. Jap J Pedod., v. 7, n. 2, p. 55-59, 1969.

17.QUIÑONEZ, R.B.; KEELS; M.A.;VANN JR, W.F.; MCIVER, F.T.; HELLER, K. Early childhood caries: analysis of psychosocial and biological factors in a high-risk population. Caries Res, v.35, p.376-383, 2001.

18. REISINE, S; LITT, M; TINANOFF, N. A biopsychosocial model to predict caries in preeschool children. Pediatr Dent , v.16, p.413-418, 1994.

19. ROCHA, C.; MIASATO, J. M.; FARINHAS, J.; SCHULLER, A. F. Diaminofluoreto de prata: uma opção em odontopediatria. Jornal Brasileiro de Odontopediatria e Odontologia do Bebê, 
v. 2, n. 8, p. 296-301, 1999.

20. RODRIGUES, C. R. M. D.; OLIVEIRA, M. M.; ANDO, T. Cariostático: Diamino fluoreto de prata. Revista da Associação Paulista de Cirurgiões Dentistas, v. 43, n. 4, p. 171-174, jul./ ago. 1989.

21. RUSSO, M.; TOMATSU, J.; TAKAYAMA, S.; HOLLAND JÚNIOR, C.; SUNDFELD R. H.; CASTRO, M. A. M.; QUINTELLAL.P.A.S.; MESTRENER S. R. Efeitos da aplicação da solução de Diamino fluoreto de prata a 38\% em dentina de dentes decíduos de cães. Revista Brasileira de Odontologia, v. 43, n. 2, p. 14-19, 1986.

22. RUSSO, M.; TOMATSU, J.; TAKAYAMA, S.; HOLLAND JÚNIOR, C.; SUNDFELDR. H.; MESTRENER S. R.; CASTRO, M.A. M.; QUINTELLA L. P. A. S. Diaminofluoreto de prata: resposta pulpar à aplicação de uma solução a $10 \%$ em dentina. RGO, v. 35, n. 4, p. 264-266, jul./ago. 1987.

23. SUZUKI, T. Studies on topical application of diammine silver fluoride for the preventive and arrestment of dental caries in human molars. Jap J Pedod, v. 11, n. 1, p. 33-54, 1973.

24. TINANOFF, N; O’SULLIVAN, D. M. Early Childhood caries: overview and recent finding. Pediatr Dent, v.19, n.1, p.12-16, 1997.

25. WAMBIER, D.S.; BOSCO, V. L. Uso de cariostático em odontopediatria: diamino fluoreto de prata. Revista de Odontopediatria, v. 4, n. 1, p. 35-41, jan./mar. 1995.

26. WAMBIER, D.S; SIMIONATO,M.R.L.; BANDEIRA,L.R.; ADIMARI,L. A. W. Avaliação de três materiais utilizados na fase preparatória do meio bucal. JBP- Jornal Brasileiro de Odontopediatria e Odontologia do Bebê, v.5, n.25, p.230-234, 2002.

27. YAMAGA, R.; NISHINO, M.; YOSHIDA, S.; YOKOMIZO, I. Diamine silver fluoride and its clinical application. J Osaka Univ Dent Sch, v. 12, p. 1-20, sept. 1972. 